\title{
Does the Japanese encephalitis virus (JEV) represent a threat for human health in Europe? Detection of JEV RNA sequences in birds collected in Italy.
}

A E Platonov ${ }^{1}$, G Rossi ${ }^{2}$, L S Karan ${ }^{1}$, K O Mironov ${ }^{1}$, L Busani³, G Rezza (giovanni.rezza@iss.it) ${ }^{3}$

1. Central Research Institute of Epidemiology, Moscow, Russia

2. School of Veterinary Medical Science, University of Camerino, Matelica, Italy

3. Istituto Superiore di Sanità (ISS, National Institute of Health), Rome, Italy

Citation style for this article:

Platonov AE, Rossi G, Karan LS, Mironov KO, Busani L, Rezza G. Does the Japanese encephalitis virus (JEV) represent a threat for human health in Europe?

Detection of JEV RNA sequences in birds collected in Italy. . Euro Surveill. 2012;17(32):pii=20241. Available online: http://www.eurosurveillance.org/ViewArticle. aspx?Articleld $=20241$

Article submitted on 30 July 2012 / published on 9 August 2012

To the editor:

Autochthonous cases of Japanese encephalitis (JE) have never been reported in Europe, where there is virtually no circulation of the virus [1]. However, in the issue of Eurosurveillance published on 12 July 2012, Ravanini et al. [2] reported the detection of an RNA sequence of the Japanese encephalitis virus (JEV) NS5 gene in one pool of Culex pipiens mosquitoes collected in north-eastern Italy during the summer of 2010. Unfortunately, the sequence was relatively short ( $167 \mathrm{bp})$, and attempts to amplify longer sequences using primers targeted to $\mathrm{E}, \mathrm{NS}_{5}$ and NS 3 genes and to isolate the virus on cell cultures failed.

To support their findings, the authors cited a previous study reporting the identification of JEV RNA in bird samples collected in Tuscany, a neighbouring Italian region, a decade before [3], and noted the lack of information on viral sequences in that study. Here we provide the results of molecular testing on bird tissue samples, which appear to confirm recent findings on JEV presence in Italy.

Between 1997 and 2000 dead birds were collected to investigate episodes of bird mortality observed in Padule del Fucecchio, a wetland area in Tuscany where cases of West Nile virus (WNV) infection in horses were observed in 1998 [4]. The episodes involved mainly blackbirds (Turdus merula) and song thrushes (Turdus philomelos). Other species, less affected by mortality, were also sampled such as rock doves (Columba livia), redwings (Turdus iliacus), sparrows (Passer italiae), and starlings (Sturnus vulgaris).

In May 2001 formalin-fixed tissue samples from seven birds collected in 2000 that tested positive for JE group antigens by immunohistochemistry, were sent to the Central Research Institute of Epidemiology in Moscow, Russia to carry out molecular testing for flaviviruses. Later, in early 2003, samples from 14 birds collected in
1997 which had also tested positive, were sent to the same Institute.

The samples were subjected to RT-PCR assays, one targeting the nonstructural NS5 gene for the detection of most flaviviruses [5] and the other for detection of the WNV and JEV envelope (E) genes (the details of these in-house assays are available from the authors on request).

None of the samples tested positive for WNV, but PCR amplicons of the JEV NS5 gene (expected size, $215 \mathrm{bp}$ ) were obtained from tissues of six birds collected in 2000. Amplicons of the JEV E gene (expected size, 687 bp) were obtained from the same six birds and in one of the birds collected in 1997. Sequencing of $552 \mathrm{bp}$ fragments of the JEV E gene from five of the samples (GenBank accession numbers AF501311-AF501315) and of NS 5 amplicons from two samples showed maximum similarity (99\%) with JEV genotype III, for example with the Nakayama strain [6].

Importantly, the JEV nucleotide sequence found in Italian Culex pipiens [2] differed from the JEV RNA sequence found in Italian birds only at two positions, which are shown bold and underlined (Italian birds, $\mathrm{NS}_{5}$ gene fragment:

C T T G G A G C A C G G TATCTAGAGTTTGA AGCTTTGGGGTTCCTGAATGAAGACCATT G GCTGAGCCGAGAGA A Y TCA G A G G T G GA T T G A A G G C T C GGGCGTCCA A A GCTAGGATACATCCTCCGTGACATAG C A G A A A G C A A G A G G A A A T GT).

However, it remains undefined whether the viruses were the same in the two episodes. To this date no human cases of JE have been reported in Italy. Thus, two different hypotheses may be considered:

- Unidentified flaviviruses highly similar to JEV but less or not virulent for humans, are circulating in Italy 
(southern Europe). This hypothesis cannot be completely ruled out until further analyses are performed.

- Limited JEV circulation has occurred between birds and mosquitoes in Italy but no human cases have been observed, as in Australia since 1995 [7]. This may be due to the relatively low availability of amplifying hosts (pigs) in that area, low vector competence of European Culex pipiens [8], low capability of local birds to maintain a persistent JEV circulation or other factors suppressing the JEV epidemic cycle $[1,6]$, and limited or absent human exposure.

In conclusion, our results seem to support the hypothesis of long distance spread of JEV from endemic areas to Europe (Italy) $[1,7]$. However, sporadic introduction of JEV to new areas by migratory birds or by other ways may not necessarily lead to local viral circulation. Moreover, the circulation of other flaviviruses closely related to JEV cannot be completely ruled out. Whether JEV represents a human health threat in Europe merits further investigation.

\section{References}

1. Erlanger TE, Weiss S, Keiser J, Utzinger J, Wiedenmayer K. Past, present, and future of Japanese encephalitis. Emerg Infect Dis. 2009;15(1):1-7.

2. Ravanini P, Huhtamo E, Ilaria V, Crobu MG, Nicosia AM, Servino L, et al. Japanese encephalitis virus RNA detected in Culex pipiens mosquitoes in Italy. Euro Surveill. 2012;17(28): pii=20221. Available from: http://www. eurosurveillance.org/ViewArticle.aspx?Articleld=20221

3. Mani P, Legrottaglie R, Bertelloni F, Fratini F, Filogari D, Rossi G. Il Virus dell'Encefalite Giapponese (JEV) in uccelli selvatici sinantropici (Passer italiae, Turdus merula, Sturnus vulgaris) e da richiamo (Turdus ilacus) in Toscana. [The Japanese encephalitis virus (JEV) in synanthropic wild birds (Passer italiae, Turdus merula, Sturnus vulgaris) and redwing (Turdus ilacus) in Tuscany]. Ecologia Urbana. 2009;21(1);99-100. Italian.

4. Autorino GL, Battisti A, Deubel V, Ferrari G, Forletta R, Giovannini A, et al. West Nile virus epidemic in horses, Tuscany region, Italy. Emerg Infect Dis. 2002;8(12):1372-8.

5. Platonov AE, Shipulin GA, Shipulina OY, Tyutyunnik EN, Frolochkina TI, Lanciotti RS, et al. Outbreak of West Nile virus infection, Volgograd Region, Russia, 1999. Emerg Infect Dis. 2001;7(1):128-32.

6. Platonov AE, Karan LS, Mironov KO, Rossi G. [On the possibility of forming a natural focus of Japanese encephalitis in southern Europe: a genetic investigation]. The 5 th All-Russian scientificpractical conference "Genetical diagnostics of infectious diseases." Moscow, 19-21 October 2004. Vol.II. P.182-4. Russian.

7. van den Hurk AF, Ritchie SA, Mackenzie JS. Ecology and geographical expansion of Japanese encephalitis virus. Annu Rev Entomol. 2009;54:17-35.

8. Turell MJ, Mores CN, Dohm DJ, Lee WJ, Kim HC, Klein TA.

Laboratory transmission of Japanese encephalitis, West Nile, and Getah viruses by mosquitoes (Diptera: Culicidae) collected near Camp Greaves, Gyeonggi Province, Republic of Korea 2003. J Med Entomol. 2006; 43(5):1076-81. 